\title{
EXPERIMENTAL STUDY ON TSUNAMI FORCES ACTING ON VERTICAL SEAWALLS UNDER OVERFLOW
}

\author{
Yukinobu Oda ${ }^{1}$, Takahide Honda ${ }^{1}$ and Teppei Omata ${ }^{1}$
}

\begin{abstract}
For tsunami seawalls installed along coastline, measures for tsunami disaster assuming overflow are required from the viewpoint of failsafe. Therefore, the tsunami force verified under overflow condition is necessary for the optimal design. Some estimation models of the tsunami forces acting on land structures have already been proposed but they were of a non-overflow condition. In this study, physical model tests for the tsunami force acting on vertical seawalls were conducted to examine the tsunami force characteristics under overflow conditions, and an estimation method of the overflowing tsunami force was proposed and verified.
\end{abstract}

Keywords: tsunami; seawalls; overflow; tsunami pressure; inundation depth

\section{INTRODUTICION}

After the 2011 Great East Japan Earthquake, tsunami disaster mitigation has been more important in Japan. It is important to accurately estimate the tsunami forces to plan the tsunami countermeasure and to evaluate the safety of structures. Some estimation models of the tsunami forces acting on land structures have already been proposed. Asakura et al. (2002) introduced the non-dimensional maximum inundation depth $\alpha$, which is defined as the ratio of the maximum passing inundation depth on the supposition that the structure did not exist to the maximum water depth on the wall of the structure, and proposed the experimental formula that the tsunami pressure can be estimated as the hydrostatic pressure. And Cabinet Office in Japanese Government (2005) issued guideline on tsunami evacuation buildings, in which the maximum water depth on a wall is three times of the maximum passing inundation depth $(\alpha=3)$. On the other hand, Sakakiyama (2014) proposed the formula for $\alpha$ as the function of Froude number based on the various numerical and physical experiment results. Oda et al. (2016) derived the similar formula for $\alpha$ by theoretical approach.

The above-mentioned estimation methods for tsunami pressure subject the non-overflow condition. For tsunami seawalls installed along coastline, tsunami disaster mitigation assuming overflow is required from the viewpoint of failsafe. Therefore, the tsunami force verified under the overflow condition is necessary for the optimal design. In this study, physical model tests for the tsunami force acting on vertical seawalls were conducted to examine the tsunami force characteristics under overflow conditions, and an estimation method of the overflowing tsunami force was proposed and verified.

\section{HYDRAULIC EXPERIMENTS}

The hydraulic experiments were performed on the two-dimensional channel with a width of $80 \mathrm{~cm}$. Two kinds of bottom profiles shown in Fig. 1, flat bottom and 1/20 slope, were applied and the vertical wall was set at the positions of P.08, P.09, and P.10, respectively. Pressure gages were installed on the wall at $5 \mathrm{~cm}$ vertical intervals to measure the tsunami-induced pressure distribution. The height of the

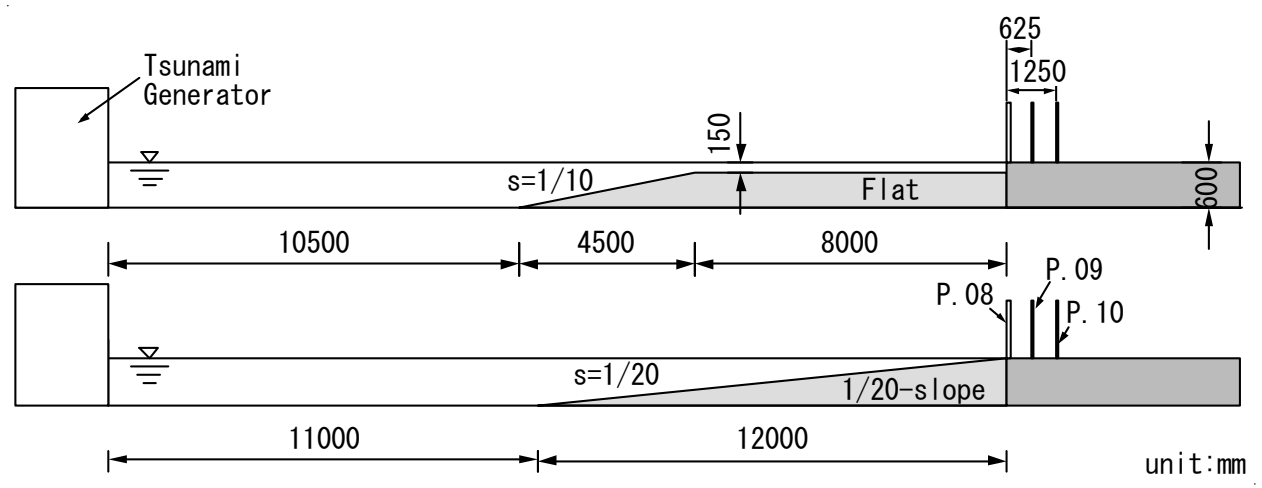

Figure 1. Schematic views of hydraulic experimental setups for two kinds of bottom profile cases.

\footnotetext{
${ }^{1}$ Technology Center, Taisei Corporation, 344-1, Nase-cho, Totsuka-ku, Yokohama, Kanagawa, 245-0051, Japan
} 
wall, $h_{d}$, changed from $0.28 \mathrm{~m}$ to $0.33 \mathrm{~m}$ so that the inundation tsunami overflow the wall structure. Additionally, the non-overflow cases were performed with the wall height of $0.8 \mathrm{~m}$, which was enough high to avoid overflow.

Tsunami waves were generated by the pneumatic tsunami generator, which can generate arbitrary wave profiles of tsunami. In the experiments, eleven tsunami profiles with three kinds of periodical characteristics and 4 kinds of tsunami height were applied. The measured tsunami profiles at $15 \mathrm{~m}$ distance from the shoreline P.08 are shown in Fig. 2.
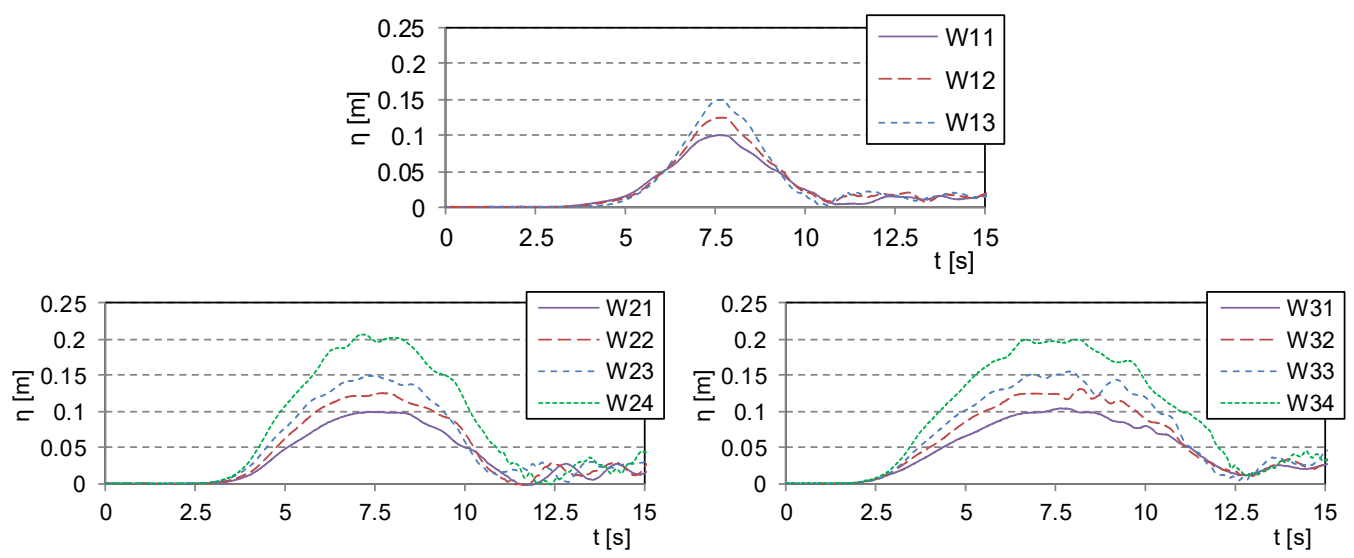

Figure 2. Measurement results of tsunami profiles at $15 \mathrm{~m}$ distance off-shore from P.08.

\section{EXPERIMENTAL RESULTS}

Figure 3 is the snapshots of the inundation tsunami around the wall structures when the maximum forces were acting on the walls for the incident tsunami case W13. In comparison with the nonoverflow case, the inundation depth of the overflow case is small. It suggested that the pressure acting on the wall is smaller than that of the non-overflow case, and evaluating the tsunami force of the overflow case assuming the pressure is the same as non-overflow case results in overestimation.
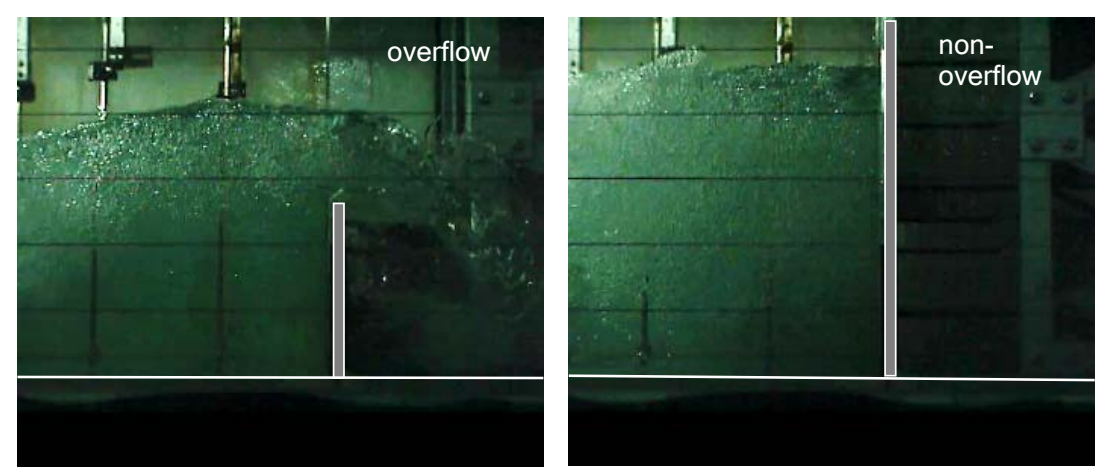

Figure 3. Snapshots when the maximum tsunami forces are acting on the walls (W13).

Figure 4 shows the tsunami force profiles acting on the wall in comparison between the nooverflow case and the overflow case. Because of the wall height, $h_{d}$, equal to 0.28 or $0.27 \mathrm{~m}$ in the overflow cases, when the tsunami inundation depth almost equal to the wall height, the tsunami force is $0.039 \mathrm{kN} / \mathrm{m}$ for case $\mathrm{W} 13$ and $0.036 \mathrm{kN} / \mathrm{m}$ for case W34, which are evaluated by $1 / 2 \rho g h_{d}^{2}$ with an assumption of hydrostatic pressure. Hence, when the tsunami forces are larger than these values, tsunami is supposed to be overflowing. In the range larger than those values, the tsunami force of nonoverflow case is significantly smaller than that of overflow case, whereas those tsunami forces in the smaller range are almost same.

Figure 5 shows the pressure distributions on the walls in a moment that the tsunami force becomes maximum, caused by the same incident tsunamis, W13 and W34. The pressure distributions above $z=$ 
0.28 or $0.27 \mathrm{~m}$ equal to zero in contrast to the non-overflow cases. Moreover, the pressure in the range of $z<h_{d}$ decreases compared with the non-overflow case. When tsunami overflows the seawall, therefore, two kinds of reduction effect of tsunami force can be confirmed: the pressure acting area decreases because of the insufficient seawall height, and the acting pressure itself also decreases because of the overflow.
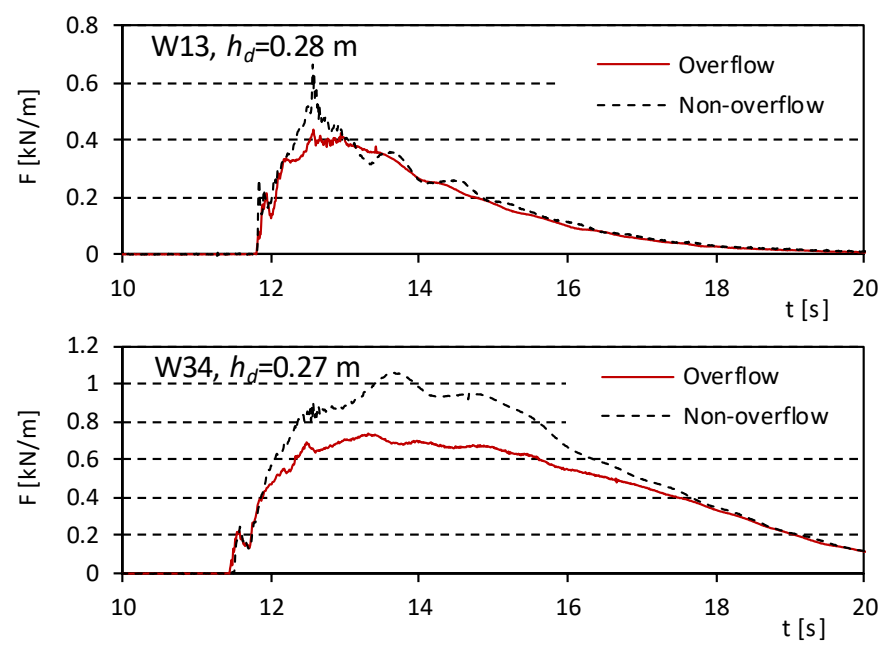

Figure 4. Tsunami force profiles acting on the walls (left: W13, right: W34).
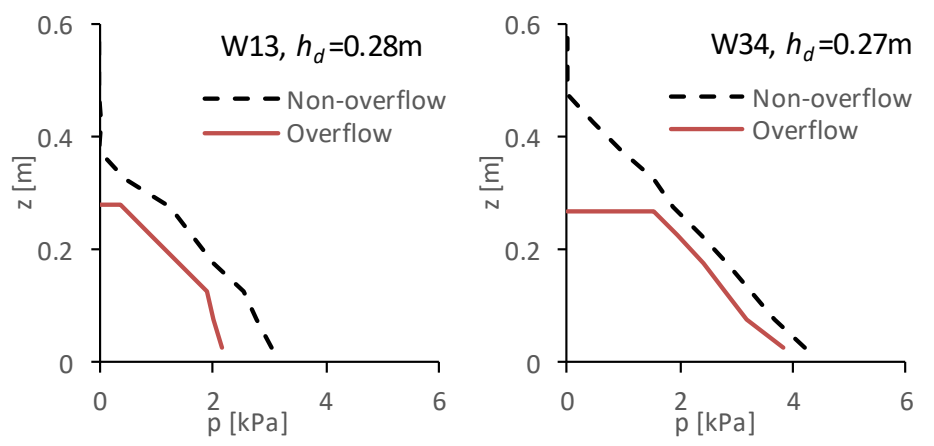

Figure 5. Hydraulic pressure distributions on the walls (left: W13, right: W34).

The analytical model is shown in Fig. 6. To discuss the reduction phenomena of the tsunami force by tsunami overflowing, the virtual tsunami force, $F^{*}$, which reflects only the effect of the cut-off pressure above the wall, is considered. $p^{*}$ is the tsunami pressure when the wall height is enough to avoid overflowing. Therefore $F^{*}$ is by the partial pressure of $p^{*}$ acting only on the overflowed wall. $F$, $p^{*}$, and $\eta^{*}$ represent the tsunami force, hydraulic pressure and corresponding inundation depth of the non-overflow case, where $\eta^{*}$ is evaluated as the equivalent depth defined as $(2 F / \rho g)^{1 / 2}$. $F^{\prime}$ and $p^{*}$, are the overflowing tsunami force and pressure, and $\eta^{*}$, denotes the corresponding inundation depth. If it is assumed that the pressure distribution can be approximated with hydrostatic pressure, $F, F^{\prime}$ and $F^{*}$ are expressed in the following equations.

$$
F=\int_{0}^{\eta^{*}} p^{*} d z=\frac{1}{2} \rho g \eta^{* 2}, F^{\prime}=\int_{0}^{h_{d}} p^{*} d z=\frac{1}{2} \rho g h_{d}\left(2 \eta^{*}-h_{d}\right), F^{*}=\int_{0}^{h_{d}} p^{*} d z=\frac{1}{2} \rho g h_{d}\left(2 \eta^{*}-h_{d}\right)
$$

Figure 7 shows the comparisons between $F, F^{\prime}$, and $F^{*}$. Figures (a), (b) and (c) represent the force reduction effects by overflowing, wall height shortage and pressure decreasing, respectively. Multiplying Fig. 7(b) and Fig. 7(c) will result in Fig. 7(a). As the tsunami force increase, the reduction rates become larger because the extent of overflow become larger. Comparing Fig. 7(b) with Fig. 7(c), 
we can see the reduction rates are almost same, and it suggested that the reduction effects by wall height shortage and pressure decreasing are of the same degree.

The tsunami force reduction rates, $F^{\prime} / F$, are compared with the relative inundation depths in Fig. 8. Here, the relative inundation depth is defined as the ratio of non-overflowing inundation depth, $\eta^{*}$, to the wall height, $h_{d} . \eta^{*} / h_{d}<1$ means the non-overflow condition. The broken line in Fig. 8 is explained later. As the relative inundation depth increases, the effect of overflowing becomes larger, so that the overflowing tsunami force becomes much smaller than the non-overflowing tsunami force. According to Fig. 8, the same characteristics can be found irrespective of the sea bottom slope and the wall position. The parameter of the horizontal axis includes $h_{d}$ and the effects of the sea bottom slope and the wall position are reflected in $h_{d}$. Therefore, if the non-overflowing inundation depth, $\eta^{*}$, is adequately evaluated, the overflowing tsunami force, $F^{\prime}$, can be estimated as the dominant value of $\eta^{*}$ and $h_{d}$ because the non-overflowing tsunami force, $F$, is also estimated as the function of $h_{d}$.

Figure 9 shows the dimensionless tsunami forces by using the non-overflowing inundation depth, $\eta^{*}$, and the wall height, $h_{d}$, where $h_{d}$ equals to $\eta^{*}$ in $\eta^{*} / h_{d}<1$. The broken and dotted lines are explained later. As the relative inundation depth increases, the dimensionless tsunami force gradually increases but it is seemed to reach the maximum value around $\eta^{*} / h_{d}=1.3$ and the experimental results are scattered less than this maximum value.

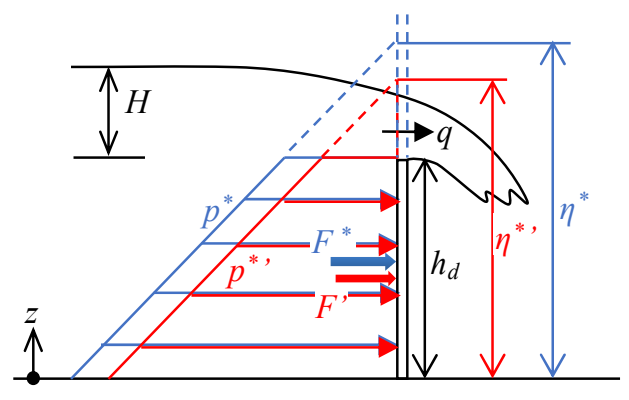

Figure 6. Analytical model of overflowing tsunami pressure.
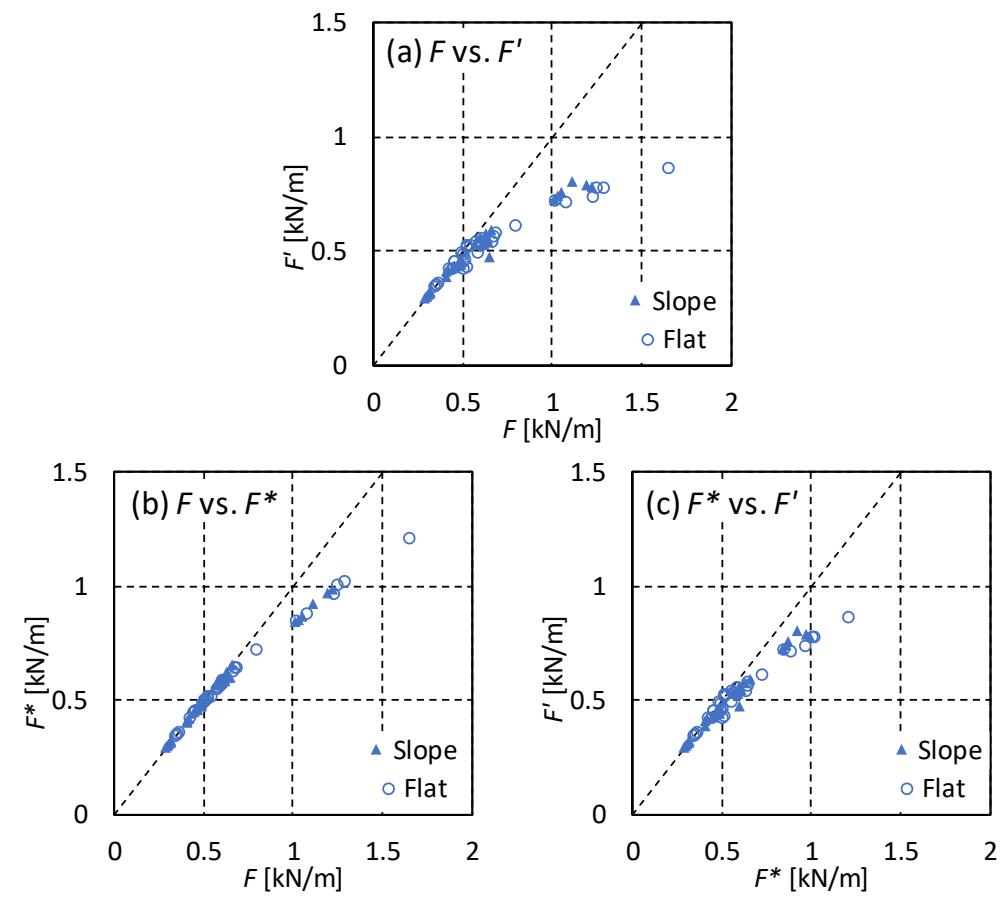

Figure 7. Comparisons of the maximum forces: non-overflow tsunami force $F$, overflow tsunami force $F$ ' and virtual tsunami force $F^{*}$. 


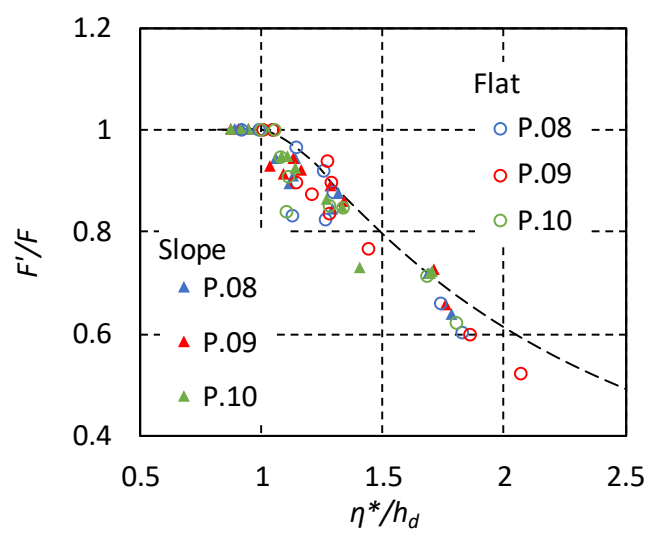

Figure 8. Tsunami force reduction due to overflow, $F^{\prime} / F$, relating to relative depth.

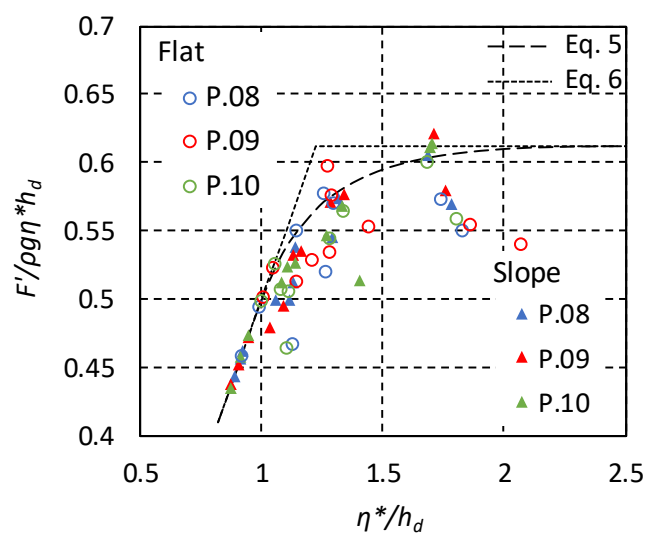

Figure 9. Dimensionless tsunami forces and the estimation results by Eq. 5 and Eq. 6.

\section{THEORITICAL DISCUSSION}

According to the analytical model shown in Fig. 6, the estimation of the overflowing tsunami force is theoretically discussed. The overflow discharge and the offshore side depth from the top of the wall are expressed as $q$ and $H$ illustrated in Fig. 6. With the assumption that $H$ is approximated by $\eta^{*},-h_{d}, q$ can be evaluated as:

$$
q=C H^{3 / 2}=C\left(\eta^{* \prime}-h_{d}\right)^{3 / 2}
$$

Here, $C$ is discharge coefficient. If it is assumed that the momentums coming from the offshore side for the overflow case and the non-overflow case are the same, the following equation is derived based on momentum conservation.

$$
\frac{1}{2} \rho g \eta^{* 2}=\frac{1}{2} \rho g \eta^{*, 2}+\rho \frac{q^{2}}{\eta^{*}-h_{d}}
$$

The left side is the hydrostatic pressure component at the wall position in the non-overflow case, and the right side is the sum of the similar pressure component and the momentum component going out to the land side over the wall in the overflow case. Then Eqs. 1, 2 and 3 yield the following equations. 


$$
\begin{gathered}
\frac{F^{\prime}}{F}=\frac{\frac{2 C^{2}}{g}-1+2 \sqrt{\left(\frac{2 C^{2}}{g}+1\right)\left(\frac{\eta^{*}}{h_{d}}\right)^{2}-\frac{2 C^{2}}{g}}}{\left(\frac{2 C^{2}}{g}+1\right)\left(\eta^{*} / h_{d}\right)^{2}} \\
\frac{F^{\prime}}{\rho g \eta^{*} h_{d}}=\frac{\frac{2 C^{2}}{g}-1+2 \sqrt{\left(\frac{2 C^{2}}{g}+1\right)\left(\frac{\eta^{*}}{h_{d}}\right)^{2}-\frac{2 C^{2}}{g}}}{2 \frac{\eta^{*}}{h_{d}}\left(\frac{2 C^{2}}{g}+1\right)}
\end{gathered}
$$

The broken lines in Figs. 8 and 9 represent the estimation result by the above equations. Here $C$ is assumed to be $\sqrt{ } g=3.13 \mathrm{~m}^{1 / 2} / \mathrm{s}$. Figs. 8 and 9 show that the proposed model envelops the upper limit and estimates the tsunami force on the safe side. It is supposed that the reason why some experimental results are smaller than the proposed model is because the discharge is underestimated, i.e. the assumptions of $H=\eta^{*}-h_{d}$ and/or $C=\sqrt{ } g$ is underestimation.

Equation 5 has a somewhat complicated form. It has the maximum value of 0.612 when $\eta^{*} / h_{d}=\sqrt{ } 6$ and it can be expressed as $0.5 \eta^{*} / h_{d}$ in $\eta^{*} / h_{d}<1$, so that we proposed the following simplified estimation equation for overflowing tsunami force on the safe side, shown as a dotted line in Fig. 9.

$$
\frac{F^{\prime}}{\rho g \eta^{*} h_{d}}=\min \left(0.5 \eta^{*} / h_{d}, 0.612\right), \quad F^{\prime}=\min \left(0.5 \rho g \eta^{* 2}, 0.612 \rho g \eta^{*} h_{d}\right)
$$

\section{CONCLUSION}

The physical model tests for the tsunami-induced forces acting on seawalls under overflow condition were conducted and the theoretical model to estimate the tsunami force was proposed based on momentum conservation. The experimental results show the factors of the tsunami force reduction due to overflowing consist of wall height shortage and pressure decreasing and they are the same degree. And if the non-overflowing inundation depth is adequately evaluated, the overflowing tsunami force can be estimated as the dominant value of $\eta^{*}$ and $h_{d}$. According to the comparison between the estimation results by the proposed model and the experimental results, the tsunami force reduction rate due to the overflow can be safely estimated by the proposed model.

\section{ACKNOWLEDGEMENTS}

This work is supported by FY2016 consignment expenses for disaster prevention measures of nuclear facility, Nuclear Regulation Authority.

\section{REFERENCES}

Asakura, R., K. Iwase, T. Ikeya, M. Takao, T. Kaneto, N. Fuji and M. Ohmori. 2002. The tsunami wave force acting on land structure, Proceedings of $28^{\text {th }}$ International Conference on Coastal Engineering, ASCE, 1191-1202.

Cabinet Office, Government of Japan. 2005. Guideline on tsunami evacuation buildings, 68p. (in Japanese)

Oda, Y., H. Honda, K. Ito and T. Takabatake. 2016. Study on Estimation of Run-up Tsunami Force Acting on a Vertical Wall Structure, Proceedings of the $7^{\text {th }}$ Civil Engineering Conference in the Asian Region, ACECC.

Sakakiyama, T., 2014. Tsunami pressure on structures due to tsunami inundation flow, Proceedings of $34^{\text {th }}$ International Conference on Coastal Engineering, structures.42. 